\title{
Lattice location of implanted transition metals in 3C-SiC
}

\author{
A R G Costa ${ }^{1}$, U Wahl ${ }^{1}$, J G Correia ${ }^{1}$, E Bosne ${ }^{1}$, L M Amorim ${ }^{2}$, \\ V Augustyns ${ }^{2}$, D J Silva ${ }^{3}, M$ R da Silva ${ }^{4}, K$ Bharuth-Ram $^{5}$ \\ and L M C Pereira ${ }^{2}$ \\ ${ }^{1}$ Centro de Ciências e Tecnologias Nucleares, Instituto Superior Técnico, Universidade de Lisboa, EN 10 ao km 139 , \\ 2695-066 Bobadela LRS, Portugal \\ ${ }^{2}$ KU Leuven, Instituut voor Kern- en Stralingsfysica, 3001 Leuven, Belgium \\ ${ }^{3}$ Centro de Física Nuclear da Universidade de Lisboa, Avenida Professor Gama Pinto 2, 1649-003 Lisboa, Portugal \\ ${ }^{4}$ Centro de Física Nuclear da Universidade de Lisboa, 1649-003 Lisboa, Portugal \\ ${ }^{5}$ Durban University of Technology, Durban 4000, South Africa \\ E-mail: angelo@ctn.tecnico.ulisboa.pt
}

Received 18 January 2017, revised 10 March 2017

Accepted for publication 22 March 2017

Published 3 May 2017

\begin{abstract}
We have investigated the lattice location of implanted transition metal (TM) ${ }^{56} \mathrm{Mn},{ }^{59} \mathrm{Fe}$ and

${ }^{65} \mathrm{Ni}$ ions in undoped single-crystalline cubic 3C-SiC by means of the emission channeling technique using radioactive isotopes produced at the CERN-ISOLDE facility. We find that in the room temperature as-implanted state, most $\mathrm{Mn}, \mathrm{Fe}$ and $\mathrm{Ni}$ atoms occupy carbon-coordinated tetrahedral interstitial sites $\left(T_{\mathrm{C}}\right)$. Smaller TM fractions were also found on $\mathrm{Si}$ substitutional $\left(S_{\mathrm{Si}}\right)$ sites. The TM atoms partially disappear from ideal- $T_{\mathrm{C}}$ positions during annealing at temperatures between $500{ }^{\circ} \mathrm{C}$ and $700{ }^{\circ} \mathrm{C}$, which is accompanied by an increase in the TM fraction occupying both $S_{\mathrm{Si}}$ sites and random sites. An explanation is given according to what is known about the annealing mechanisms of silicon vacancies in silicon carbide. The origin of the observed lattice sites and their changes with thermal annealing are discussed and compared to the case of $\mathrm{Si}$, highlighting the feature that the interstitial migration of TMs in $\mathrm{SiC}$ is much slower than in $\mathrm{Si}$.
\end{abstract}

Keywords: channeling, lattice location, ion implantation, silicon carbide, transition metals

https://doi.org/10.1088/1361-6463/aa6878

Supplementary material for this article is available online (Some figures may appear in colour only in the online journal)

\section{Introduction}

Silicon carbide ( $\mathrm{SiC}$ ) is a wide-band-gap semiconductor with an increasing number of applications. It is able to work not only at high temperatures but also in high-power, highfrequency and high-radiation environments [1-4]. These properties make it possible to replace mainstream siliconbased power devices with outperforming SiC-based ones. Until recently, the development of $\mathrm{SiC}$ electronic devices was hindered by $\mathrm{SiC}$ material costs and wafer growth technology. Small wafer sizes and the presence of point and extended defects were major obstacles. Today, with these obstacles being steadily overcome, we can observe a rapid development of $\mathrm{SiC}$ technology and applications. Currently, most $\mathrm{SiC}$ devices are based on the $4 \mathrm{H}$ polytype $[3,4]$ with a bandgap of $E_{\mathrm{g}}=3.2 \mathrm{eV}$, but $6 \mathrm{H}\left(E_{\mathrm{g}}=3.0 \mathrm{eV}\right)$ and $3 \mathrm{C}\left(E_{\mathrm{g}}=\right.$ $2.4 \mathrm{eV}$ ) polytypes are also being considered for specific applications. While, for instance, 3C-SiC possesses the smallest bandgap of all known $\mathrm{SiC}$ polytypes, its electron mobility is superior to its $4 \mathrm{H}$ and $6 \mathrm{H}$ counterparts, which for certain device applications proves to be advantageous $[3,4]$. Still, a basic understanding of how specific defects affect the reliability of $\mathrm{SiC}$ devices based on any polytype is poor [4]. Transition metal (TM) impurities are invariably found in bulk samples of $\mathrm{SiC}[5,6]$ due to the production processes normally employed. It is known that those impuri- 
ties, either in their isolated form or when in complexes with other defects, generate electrically active levels deep in the band gap of $\mathrm{SiC}$, changing its electrical properties and thus affecting the performance of devices [6-8]. On the other hand, by using intentional doping with TM atoms, one can also beneficially vary the electrical, optical and magnetic properties of SiC. For example, the introduction of vanadium compensates the excess of nitrogen, an undesirable electrically active impurity in the semi-insulating $\mathrm{SiC}$ single crystal growth process [9]. Substitutional doping with TMs (e.g. $\mathrm{Cr}, \mathrm{Mn}, \mathrm{Fe}$ ) has also been considered in the context of dilute magnetic semiconductors [10-14].

Currently, hardly any experimental data exist on the preferential lattice sites that TM impurities occupy in any of the SiC polytypes, whereas several theoretical studies exist. Machado et al [14] found that $\mathrm{Mn}$ and $\mathrm{Fe}$ in $2 \mathrm{H}-\mathrm{SiC}$ 'are energetically more favorable in lattice sites with carbon atoms as their first nearest neighbors, in both substitutional and interstitial configurations, which results from the larger electronegativity of carbon with respect to that of silicon'; in the case of $\mathrm{Fe}$ in $3 \mathrm{C}-\mathrm{SiC}$, similar site preferences were also suggested in [15]. While [12, 16] investigated most $\mathrm{TMs}$ in $3 \mathrm{C}-\mathrm{SiC}$, including $\mathrm{Mn}, \mathrm{Fe}$ and $\mathrm{Ni}$, only substitutional sites were addressed, of which the Si sites were considered most stable. On the other hand, [17] predicts that $\mathrm{Cr}, \mathrm{Fe}$ and $\mathrm{Co}$ should predominantly occupy $\mathrm{C}$ sites while Mn should prefer to be found on Si sites. Moreover, entirely different lattice sites might also be found. For instance, the existence of mixed divacancies $V_{\mathrm{Si}}-V_{\mathrm{C}}$ is reported in [1820]. While one expects that single vacancies $V_{\mathrm{Si}}$ or $V_{\mathrm{C}}$ might trap interstitial TM atoms on substitutional $\mathrm{Si}$ or $\mathrm{C}$ sites, divacancies $V_{\mathrm{Si}}-V_{\mathrm{C}}$ might trap $\mathrm{TMs}$ in $V_{\mathrm{Si}}-\mathrm{TM}-V_{\mathrm{C}}$ complexes where the position of the TM may correspond to the bond-center (BC) site in an undisturbed lattice. Such complexes have been suggested to be those most commonly found for ion-implanted TMs in Si [21-25].

In this work, the lattice locations of the radioactive isotopes ${ }^{56} \mathrm{Mn},{ }^{59} \mathrm{Fe}$ and ${ }^{65} \mathrm{Ni}$ implanted into $3 \mathrm{C}-\mathrm{SiC}$ single crystals were investigated by means of the emission channeling (EC) technique $[26,27]$ as a function of the annealing temperature. We have first addressed $3 \mathrm{C}-\mathrm{SiC}$ due to the simplicity of its cubic structure compared to other polytypes and our previous experience with lattice location experiments in diamond and zincblende type semiconductors; results for $\mathrm{TMs}$ in $6 \mathrm{H}-\mathrm{SiC}$ were recently also obtained but will be published separately [28]. ${ }^{56} \mathrm{Mn},{ }^{59} \mathrm{Fe}$ and ${ }^{65} \mathrm{Ni}$ decay to the stable isotopes ${ }^{56} \mathrm{Fe},{ }^{59} \mathrm{Co}$ and ${ }^{65} \mathrm{Cu}$ (see table 1 ) by means of beta $\left(\beta^{-}\right)$emission, and the EC technique is based on the observation of anisotropic $\beta^{-}$intensity patterns emitted when radioactive probe atoms are embedded in single crystals. Depending on the lattice site of the emitter atoms, the $\beta^{-}$particles may be guided, or channeled, by the crystal potentials within a few degrees (of the order of magnitude of the critical angle $\psi_{\mathrm{c}}$, see table 1 ) of the principal crystallographic axes, on their way out of the crystal. The angular distribution of the emitted $\beta^{-}$particles, which can be measured with a position-sensitive electron detector, depends on both the crystallographic axis and on the position of the emitting atoms within the lattice. The experimental patterns are then compared to simulations, which allow one to iden- tify and quantify the site occupancy of the probe atoms. Specifically, for ${ }^{59} \mathrm{Fe}$, the results will also be compared with the results obtained from ${ }^{57} \mathrm{Mn} \rightarrow{ }^{57} \mathrm{Fe}$ emission Mössbauer spectroscopy (MS) [29, 30].

\section{Experiment}

\subsection{Experimental details}

Three undoped single-crystalline cubic 3C-SiC samples with $\langle 100\rangle$ oriented surfaces were used, all obtained from Hoya Corporation (Japan). Mass-separated and chemically clean beams of radioactive isotopes were provided by the online isotope separator ISOLDE-CERN [31]. The TM radioisotopes were produced by fission of uranium carbide $\mathrm{UC}_{2}$ targets, induced by $1.4 \mathrm{GeV}$ proton beams from the CERN PS-Booster, followed by chemically selective laser ionization and electromagnetic mass separation. In order to study $\mathrm{Mn}$ and $\mathrm{Ni}$, the short-lived isotopes ${ }^{56} \mathrm{Mn}$ and ${ }^{65} \mathrm{Ni}$ were implanted directly. Since ISOLDE cannot produce clean beams of Fe isotopes, to study the lattice location of this element the shortlived precursor isotope ${ }^{59} \mathrm{Mn}\left(t_{1 / 2}=\right.$ $4.6 \mathrm{~s})$ was implanted, which decays into the long-lived ${ }^{59} \mathrm{Fe}$. Note that, during the decay of ${ }^{59} \mathrm{Mn}$, the ${ }^{59} \mathrm{Fe}$ daughter atoms receive mean recoil energies of $200 \mathrm{eV}$, assuring their re-implantation and thus avoiding any influence from the previous site of ${ }^{59} \mathrm{Mn}$.

The implantations were carried out at room temperature (RT) under vacuum better than $10^{-5}$ mbar and at a tilt angle of $17^{\circ}$ from the $\langle 100\rangle$ surface with a twist of several degrees from the $\{110\}$ plane to avoid channeling effects. The implantations were made through an aperture of $1 \mathrm{~mm}$ diameter with the implantation energies and total fluences listed in table 2. While in the case of the long-lived isotope ${ }^{59} \mathrm{Fe}$, the complete activity required for the whole experiment was implanted in one step, for the short-lived probe atoms ${ }^{56} \mathrm{Mn}$ and ${ }^{65} \mathrm{Ni}$, five respective ten smaller incremental implantations into the same spot on the sample were performed, each providing enough activity for one or two annealing steps. Isochronal annealing was performed in situ up to $900{ }^{\circ} \mathrm{C}$ for 10 min at steps of $100^{\circ} \mathrm{C}$, followed by EC measurements at RT. Data acquisition times were typically 5-30 min per pattern for the short-lived isotopes but around 1-3 days per pattern for ${ }^{59} \mathrm{Fe}$. Detailed information about the EC experimental apparatus is given in [34].

Stopping and range of ions in matter (SRIM) [35] simulations show that each implanted ${ }^{56} \mathrm{Mn},{ }^{59} \mathrm{Fe}$ and ${ }^{65} \mathrm{Ni}$ ion produces around 600-800 vacancies and interstitials. The corresponding range, straggle and peak concentrations estimated for Gaussian implantation profiles are listed in table 2 . The $\beta^{-}$emission yields were measured within $\pm 3^{\circ}$ of the $\langle 100\rangle,\langle 110\rangle,\langle 111\rangle$ and $\langle 211\rangle$ crystallographic directions using a position- and energy-sensitive electron detector [27, 36]. Effects due to the background from $\gamma$-rays and $\beta^{-}$particles scattered by the chamber walls were corrected as follows. The contribution from $\gamma$-rays was determined by measuring the background count rate when a shutter was placed in front of the detector, resulting in $\sim 10 \%$ of the total count rate for the experiments presented here. 
Table 1. Properties of the radioisotopes used in this study. The $\beta^{-}$decay characteristics (including detailed $\beta^{-}$energy distributions, which we have included in the supplementary material, available at stacks.iop.org/JPhysD/50/215101/mmedia) were obtained from the JEFF-3.1 database [33]. In addition, the Lindhard critical angles $\psi_{\mathrm{c}}$ for channeling along the $3 \mathrm{C}-\mathrm{SiC}\langle 111\rangle$ direction are given according to $\psi_{\mathrm{c}}=$ $\left[2 Z_{1} Z_{2} e^{2} / E d\right]^{1 / 2}$, where $e$ is the electron charge, $Z_{1}=1$ its charge number and $Z_{2} / d=$ the total nuclear charge number per unit length $d$ of the channeling direction, i.e. for $\operatorname{SiC}\langle 111\rangle Z_{2} / d=(14+6) / 7.55 \AA$, and as kinetic energy $E$ we have used the average $\beta^{-}$energy. Note that the critical angles are given here only to qualitatively illustrate that the angular widths of electron EC effects are considerably different for the three isotopes, while $\psi_{\mathrm{c}}$ is not a parameter used in the 'many-beam' simulations described below.

\begin{tabular}{llllll}
\hline Radioisotope & Half life & $\begin{array}{l}\text { Stable decay } \\
\text { product }\end{array}$ & $\begin{array}{l}\beta^{-} \text {endpoint } \\
\text { energy }(\mathrm{keV})\end{array}$ & $\begin{array}{l}\text { Average } \beta^{-} \\
\text {energy }(\mathrm{keV})\end{array}$ & $\begin{array}{l}\text { Critical angle } \psi_{\mathrm{c}} \\
\text { for } 3 \mathrm{C}-\mathrm{SiC}\langle 111\rangle\end{array}$ \\
\hline${ }^{56} \mathrm{Mn}$ & $2.58 \mathrm{~h}$ & ${ }^{56} \mathrm{Fe}$ & 2849 & 821 & $0.55^{\circ}$ \\
${ }^{59} \mathrm{Fe}$ & $44.5 \mathrm{~d}$ & ${ }^{59} \mathrm{Co}$ & 466 & 118 & $1.46^{\circ}$ \\
${ }^{65} \mathrm{Ni}$ & $2.52 \mathrm{~h}$ & ${ }^{65} \mathrm{Cu}$ & 2136 & 630 & $0.63^{\circ}$ \\
\hline
\end{tabular}

Table 2. Implantation energy and total fluence for the various experiments. The corresponding projected range, straggling and peak concentrations were calculated by SRIM [34].

\begin{tabular}{llllll}
\hline TM probe & $\begin{array}{l}\text { Implantation } \\
\text { energy }(\mathrm{keV})\end{array}$ & $\begin{array}{l}\text { Fluence } \\
\left(\mathrm{at} \cdot \mathrm{cm}^{-2}\right)\end{array}$ & $\begin{array}{l}\text { Projected } \\
\text { range } R_{\mathrm{p}}(\AA)\end{array}$ & $\begin{array}{l}\text { Straggling } \\
(\AA)\end{array}$ & $\begin{array}{l}\text { Peak concentration } \\
\left(\mathrm{cm}^{-3}\right)\end{array}$ \\
\hline${ }^{56} \mathrm{Mn}$ & 40 & $2 \times 10^{13}$ & 256 & 93 & $8 \times 10^{18}$ \\
${ }^{59} \mathrm{Fe}$ & 40 & $3 \times 10^{13}$ & 259 & 98 & $1 \times 10^{19}$ \\
${ }^{65} \mathrm{Ni}$ & 50 & $6 \times 10^{13}$ & 298 & 110 & $2 \times 10^{19}$ \\
\hline
\end{tabular}

Table 3. Root mean square (rms) displacements $u_{1}$ of $\mathrm{Si}$ and $\mathrm{C}$ atoms in various $\mathrm{SiC}$ polytypes according to the cited references. We include Debye temperatures that we have derived from the $u_{1}$ values using the Debye theory. $T_{\mathrm{D}}(\mathrm{SiC})$ was estimated according to $T_{\mathrm{D}}(\mathrm{SiC})$ $=1 / 2\left[T_{\mathrm{D}}(\mathrm{Si})\left(M_{\mathrm{Si}} / M_{\mathrm{av}}\right)^{1 / 2}+T_{\mathrm{D}}(\mathrm{C})\left(M_{\mathrm{C}} / M_{\mathrm{av}}\right)^{1 / 2}\right]$ with $M_{\mathrm{av}}=20$. Note that the Debye temperatures are given only for completeness, they are not needed in our many-beam simulations, which depend only on $u_{1}$ values.

\begin{tabular}{lllllll}
\hline SiC polytype & $u_{1}(\mathrm{Si})(\AA)$ & $u_{1}(\mathrm{C})(\AA)$ & $T_{\mathrm{D}}(\mathrm{Si})(\mathrm{K})$ & $T_{\mathrm{D}}(\mathrm{C})(\mathrm{K})$ & $T_{\mathrm{D}}(\mathrm{SiC})(\mathrm{K})$ & $\mathrm{Reference}$ \\
\hline $2 \mathrm{H}$ & 0.060 & 0.061 & 692 & 1142 & 851 & {$[38]$} \\
$4 \mathrm{H}$ & 0.070 & 0.070 & 589 & 966 & 723 & {$[39]$} \\
$4 \mathrm{H}$ & 0.041 & 0.054 & 1120 & 1351 & 1186 & {$[40]$} \\
$6 \mathrm{H}$ & 0.051 & 0.057 & 843 & 1254 & 984 & {$[41]$} \\
'Microcrystalline' & 0.034 & 0.048 & 1434 & 1610 & 1472 & {$[42]$} \\
\hline
\end{tabular}

The background of $\beta^{-}$particles scattered into the detector was estimated with the Monte Carlo GEANT4 code [37] as being $\sim 50 \%$ for ${ }^{59} \mathrm{Fe}$ and $\sim{ }^{54} \%$ for ${ }^{56} \mathrm{Mn}$ and ${ }^{65} \mathrm{Ni}$. To correct for both types of background, the fractions of probe atoms on specific lattice sites obtained by the fitting procedures described below were multiplied with corresponding correction factors. Note that this procedure is completely equivalent to subtracting a flat background value from the experimental electron yields before fit analysis with the theoretical patterns.

\subsection{Lattice sites}

Theoretical $\beta^{-}$emission yield patterns for ${ }^{56} \mathrm{Mn},{ }^{59} \mathrm{Fe}$ and ${ }^{65} \mathrm{Ni}$ were obtained with the 'many-beam' formalism for electron channeling in single crystals [26, 27] for all relevant high symmetry sites in the $\mathrm{SiC}$ zincblende structure such as the substitutional $\mathrm{Si}\left(S_{\mathrm{Si}}\right)$ and $\mathrm{C}\left(S_{\mathrm{C}}\right)$ sites. Since this is our first publication reporting many-beam simulations for $\mathrm{SiC}$, we mention a few of the key parameters used; further details on the implementatio $4 \mathrm{n}$ of the isotopes ${ }^{56} \mathrm{Mn},{ }^{59} \mathrm{Fe}$ and ${ }^{65} \mathrm{Ni}$ can be found in the supplemental material (stacks.iop.org/JPhysD/50/215101/mmedia). The crystal potential was approximated by a superposition of atomic potentials calculated in the Doyle-Turner representation, using the coefficients $a_{i}$ and $b_{i}$ for $\mathrm{Si}$ and $\mathrm{C}$ tabulated in [37] and a lattice constant for cubic SiC of $a=4.3596 \AA$. For simulation of the EC patterns, root mean square (rms) displacements $u_{1}$ based on structural characterization methods such as x-ray diffraction or neutron scattering have been preferred as input parameters, rather than rms displacements derived from Debye temperatures that are, for example, estimated from measurements of calorimetric properties, elastic constants or similar techniques, or theoretically calculated from first principles. To our knowledge, there are no experimental data to be found in the literature on the rms displacements of $\mathrm{Si}$ and $\mathrm{C}$ atoms in $3 \mathrm{C}-\mathrm{SiC}$; they exist only for $2 \mathrm{H}-[38], 4 \mathrm{H}-$ [39] and $6 \mathrm{H}-[40,41]$ or unspecified microcrystalline - SiC [42] (table 3). We have adopted the rms displacements of [38], $u_{1}(\mathrm{Si})=0.0603 \AA$ and $u_{1}(\mathrm{C})=$ $0.0611 \AA$; however, since the values scatter considerably, for comparison, some simulations were also performed using smaller values of $u_{1}(\mathrm{Si})=0.0440 \AA$ and $u_{1}(\mathrm{C})=$ $0.0490 \AA$.

Examples of possible lattice sites with high symmetry in the cubic SiC structure are shown in figure 1. A multitude of potential interstitial sites exist and yields were also simulated for: the tetrahedral interstitial sites with $\mathrm{Si}\left(T_{\mathrm{Si}}\right)$ and $\mathrm{C}$ $\left(T_{\mathrm{C}}\right)$ nearest neighbors; interstitial sites along the $\langle 111\rangle \mathrm{di}-$ rection - bond center $(\mathrm{BC})$, antibonding $\mathrm{Si}\left(\mathrm{AB}_{\mathrm{Si}}\right)$, antibonding $\mathrm{C}\left(\mathrm{AB}_{\mathrm{C}}\right)$ and the hexagonal site $(\mathrm{H})$; interstitial 


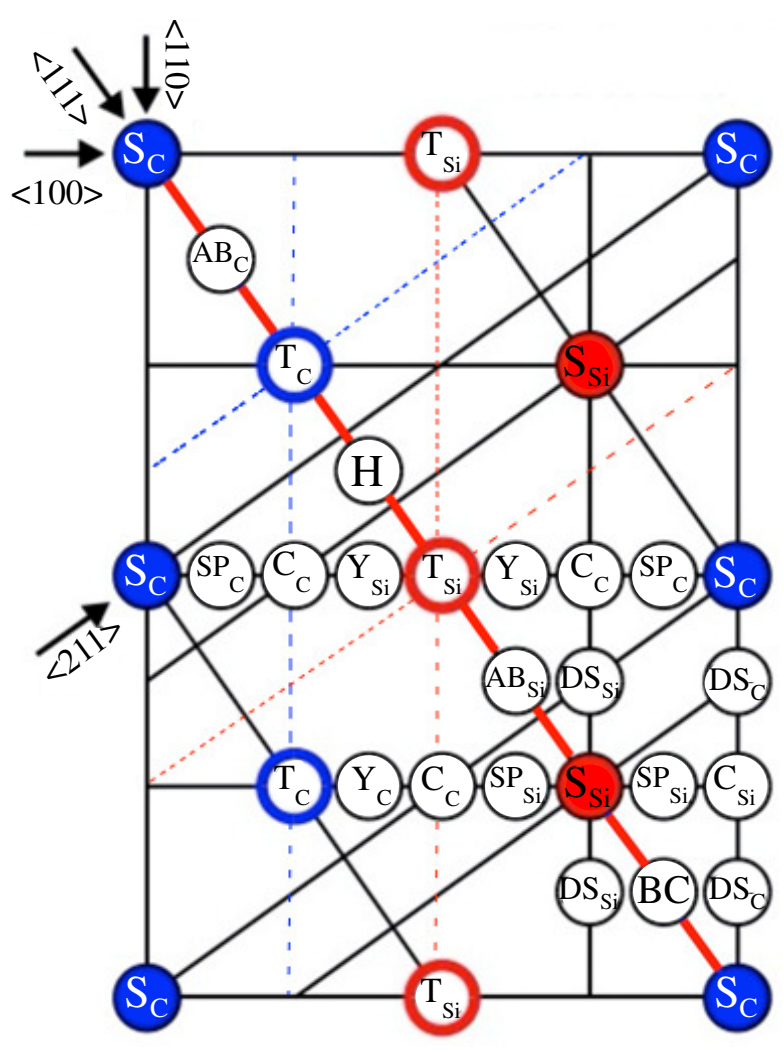

Figure 1. Positions of the major sites in the $3 \mathrm{C}-\mathrm{SiC}$ lattice, shown in the $\{110\}$ plane. Note that along the $\langle 111\rangle$ direction the substitutional $\left(S_{\mathrm{Si}}\right.$ and $\left.S_{\mathrm{C}}\right)$ and tetrahedral interstitial $\left(T_{\mathrm{Si}}\right.$ and $\left.T_{\mathrm{C}}\right)$ sites are all located on the same row; along the $\langle 100\rangle$ direction $S_{\mathrm{Si}}$ is on the same row as $T_{\mathrm{C}}$ while $S_{\mathrm{C}}$ is on the same row as $T_{\mathrm{Si}}$.

sites along the $\langle 100\rangle$ direction in either $\mathrm{Si}$ or $\mathrm{C}$ rows, i.e. the split interstitials $\left(\mathrm{SP}_{\mathrm{Si}}\right.$ and $\left.\mathrm{SP}_{\mathrm{C}}\right)$; the ' $\mathrm{C}$ ' sites with $\mathrm{C}_{2 v}$ symmetry $\left(\mathrm{C}_{\mathrm{Si}}\right.$ and $\left.\mathrm{C}_{\mathrm{C}}\right)$; and the ' $\mathrm{Y}$ ' sites $\left(\mathrm{Y}_{\mathrm{Si}}\right.$ and $\left.\mathrm{Y}_{\mathrm{C}}\right)$ and interstitial sites along the $\langle 110\rangle$ direction, i.e. the 'DS' sites $\left(\mathrm{DS}_{\mathrm{Si}}\right.$ and $\left.\mathrm{DS}_{\mathrm{C}}\right)$.

Figure 2 shows the calculated characteristic twodimensional patterns of electron emission probability within a range of $\pm 3^{\circ}$ around the $\langle 100\rangle,\langle 110\rangle,\langle 111\rangle$ and $\langle 211\rangle$ axes in angular steps of $\Delta x=\Delta y=0.05^{\circ}$ for $100 \%$ of ${ }^{56} \mathrm{Mn}$ atoms on substitutional sites $\left(S_{\mathrm{Si}}\right.$ and $\left.S_{\mathrm{C}}\right)$ and tetrahedral interstitial $\left(T_{\mathrm{C}}\right.$ and $\left.T_{\mathrm{Si}}\right)$ sites.

Since the $S_{\mathrm{Si}}, S_{\mathrm{C}}, T_{\mathrm{Si}}$ and $T_{\mathrm{C}}$ sites are located on the same row along the $\langle 111\rangle$ axis, they are all equivalent in the lattice projection onto the plane perpendicular to the $\langle 111\rangle$ direction and, consequently, the corresponding $\langle 111\rangle$ emission patterns are indistinguishable (figure 2, third column). Similarly, along the $\langle 100\rangle$ direction, since $S_{\mathrm{Si}}$ is on the same row as $T_{\mathrm{C}}$, and $S_{\mathrm{C}}$ is on the same row as $T_{\mathrm{Si}}$, the corresponding $\langle 100\rangle$ emission patterns are indistinguishable (figure 2 , first column).

In order to distinguish between these sites, it is necessary to measure channeling patterns along the $\langle 110\rangle$ and $\langle 211\rangle$ directions, which puts the different sites in different rows (see the dashed lines in figure 1). This results in emission patterns with clearly distinct anisotropies and thus allows for the unambiguous identification of the occupied lattice sites. Note that simulated ${ }^{59} \mathrm{Fe}$ and ${ }^{65} \mathrm{Ni} \beta^{-}$emission yields have similar patterns as ${ }^{56} \mathrm{Mn}$ and are therefore not shown.

\section{Results and discussion}

The two-dimensional experimental patterns were fitted by considering that fractions of TM probe nuclei occupy several different lattice sites. The fitting procedures comparing the theoretical yields and experimental patterns take into account the angular resolution of the detection setup and have been described elsewhere [27, 35]. Note that the experimental results can only be satisfactorily described if, in addition to the fractions of probe atoms on regular sites, we also allow for a fraction on 'random' sites, which contributes an isotropic emission yield. On the one hand, this socalled 'random fraction' accounts for probe atoms that occupy sites of low crystallographic symmetry, or even within amorphous surroundings, which both cause negligible channeling effects; on the other hand, the random fraction also results from initially channeled electrons which were dechanneled on their way out of the crystal due to interactions with crystal defects. A large random fraction may thus be the consequence of crystal damage from the implantation process, while its decrease (i.e. an increase of the sum of all regular site fractions) indicates annealing of this damage.

In the fitting process, we first considered single fractions on regular sites and concluded that two main types of sites contribute to the best fits, depending on the annealing temperature. For low annealing temperatures $\left(<500{ }^{\circ} \mathrm{C}\right)$, the best fits for all three investigated TMs were obtained with the ideal tetrahedral, carbon-coordinated, interstitial site $\left(T_{\mathrm{C}}\right)$. For annealing temperatures above $500{ }^{\circ} \mathrm{C}$, the best fits were obtained for ideal substitutional silicon $\left(S_{\mathrm{Si}}\right)$ sites. Indeed, it is possible to visually identify this site change for all three measured TM probes by comparing the $\langle 110\rangle$ and $\langle 211\rangle$ pattern directions (figures 3 and 4 ) to the corresponding patterns for the various substitutional and tetrahedral interstitial sites (figure 2).

In figure 3 we have patterns that are best described by assuming that the TM probe atoms are in an interstitial site. However, in figures 4 and 5, the patterns are characteristic for probe atoms in substitutional sites. The next step in the analysis was to allow the fitting routine to include two ideal lattice sites simultaneously. In this case, the combination of ideal $S_{\mathrm{Si}}+T_{\mathrm{C}}$ sites gave the best fit with a $50 \%$ improvement of the chi square $\left(\chi^{2}\right)$ compared to the single fraction fit.

In order to further improve $\chi^{2}$, we explored the possibility of simultaneous occupancy of sites that are displaced from ideal $S_{\mathrm{Si}}$ or $T_{\mathrm{C}}$ positions. However, displacements from the ideal $T_{\mathrm{C}}$ site did not improve fit quality in contrast to fixing the $T_{\mathrm{C}}$ site on its ideal position and allowing the other site fraction to move away from the $S_{\mathrm{Si}}$ site along the $\langle 111\rangle$ direction towards neighboring $\mathrm{AB}_{\mathrm{Si}}$ or $\mathrm{BC}$ sites, or along the $\langle 100\rangle$ direction towards $\mathrm{SP}_{\mathrm{Si}}$ sites, or along the $\langle 110\rangle$ direction towards $\mathrm{DS}_{\mathrm{Si}}$ sites.

The chi squares obtained from fits to the $\langle 110\rangle$ and $\langle 211\rangle$ patterns as a function of displacement from ideal $S_{\mathrm{Si}}$ sites are shown in figure 6 . Note that the experimental channel- 


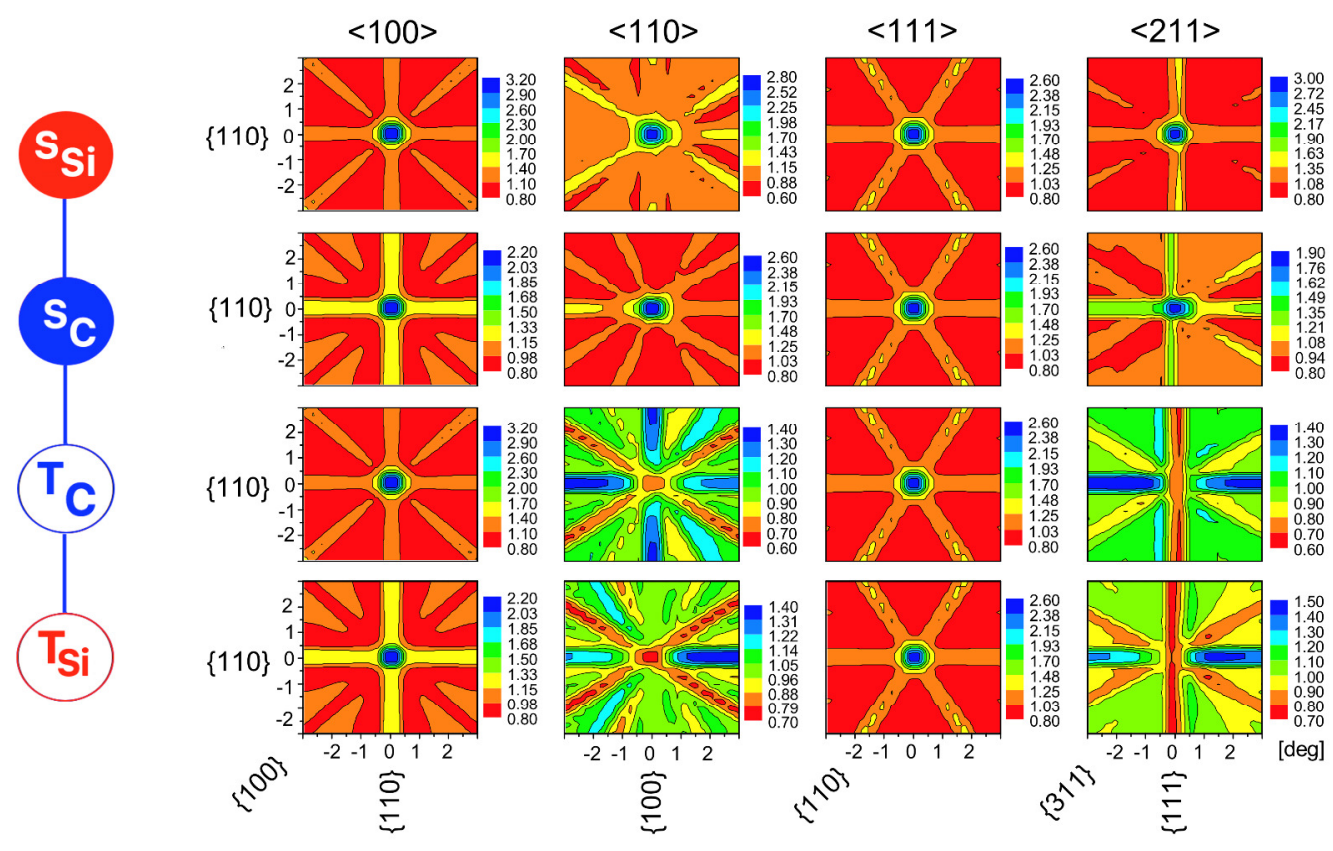

Figure 2. Simulated ${ }^{56} \mathrm{Mn} \beta^{-}$emission yield patterns for the sequence of sites along the $\langle 111\rangle$ direction, $S_{\mathrm{Si}} \rightarrow S_{\mathrm{C}} \rightarrow T_{\mathrm{C}} \rightarrow T_{\mathrm{Si}}$, around $\langle 100\rangle,\langle 110\rangle,\langle 111\rangle$ and $\langle 211\rangle$ directions. The patterns of $S_{\mathrm{Si}}$ and $S_{\mathrm{C}}$ sites are characterized by channeling peaks from all the four axial orientations shown as well as along all planes. For the interstitial $T_{\mathrm{Si}}$ and $T_{\mathrm{C}}$ sites one has, depending on the axial or planar direction, channeling or blocking effects.
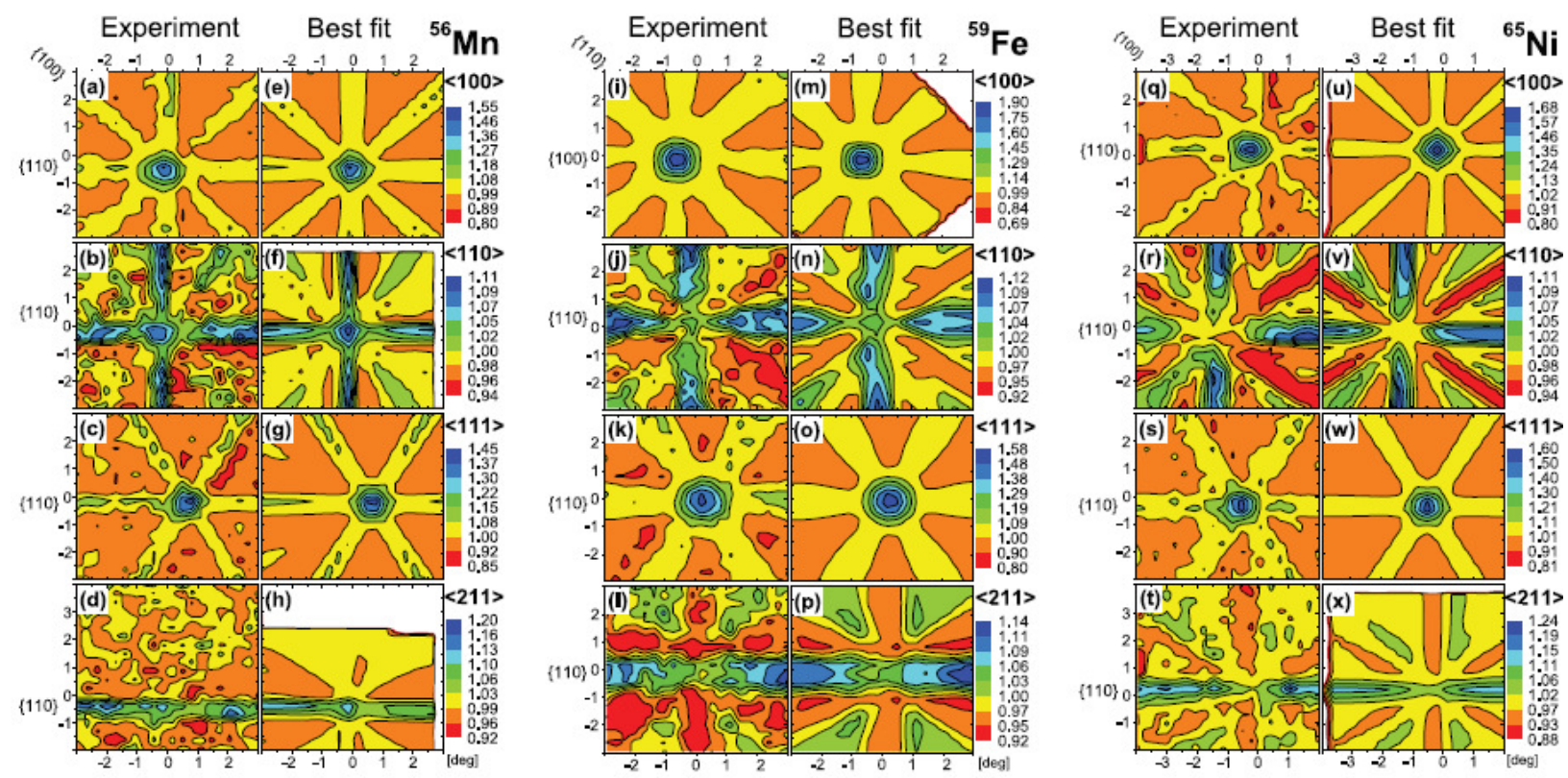

Figure 3. Normalized experimental $\beta^{-}$EC patterns and corresponding best fits for a combination of near- $S_{\mathrm{Si}}$ and ideal- $T_{\mathrm{C}}$ sites along the $\langle 100\rangle,\langle 110\rangle,\langle 111\rangle$ and $\langle 211\rangle$ directions following ${ }^{56} \mathrm{Mn}(\mathrm{a})-(\mathrm{d}),{ }^{59} \mathrm{Fe}(\mathrm{i})-(\mathrm{l})$ and ${ }^{65} \mathrm{Ni}(\mathrm{q})-(\mathrm{t})$ implantations at RT. Note that in some cases the crystal was oriented during the experiment in such a way that the recorded patterns include areas which were further than $3^{\circ}$ away from the major crystallographic direction. Since the 'manybeam' simulations were restricted to an angular range of $\pm 3^{\circ}$ from the axes, the corresponding areas along the edges or corners of patterns (f), (h), (m), (u) and (x) are shown in white.

ing patterns along the $\langle 100\rangle$ and $\langle 111\rangle$ axial directions are not suitable for such a procedure since both $T_{\mathrm{C}}$ and $S_{\mathrm{Si}}$ sites are located within rows of $\mathrm{Si}$ atoms along those directions. The $\langle 100\rangle$ and $\langle 111\rangle$ channeling patterns resulting from ideal $T_{\mathrm{C}}$ and slightly displaced $S_{\mathrm{Si}}$ sites are hence too similar and the fits tend to become unstable. The dashed and full arrows in figure 6 indicate the TM probe positions for which the chi squares of the $\langle 110\rangle$ and $\langle 211\rangle$ fits were minimized. This suggests that the three TM atoms are slightly displaced $\left(\sim 0.1-0.3 \AA\right.$ ) from the ideal $S_{\mathrm{Si}}$ sites. However, the improvements in the $\chi^{2}$ norm for displacements along the different axial directions were, for all isotopes and anneal- 

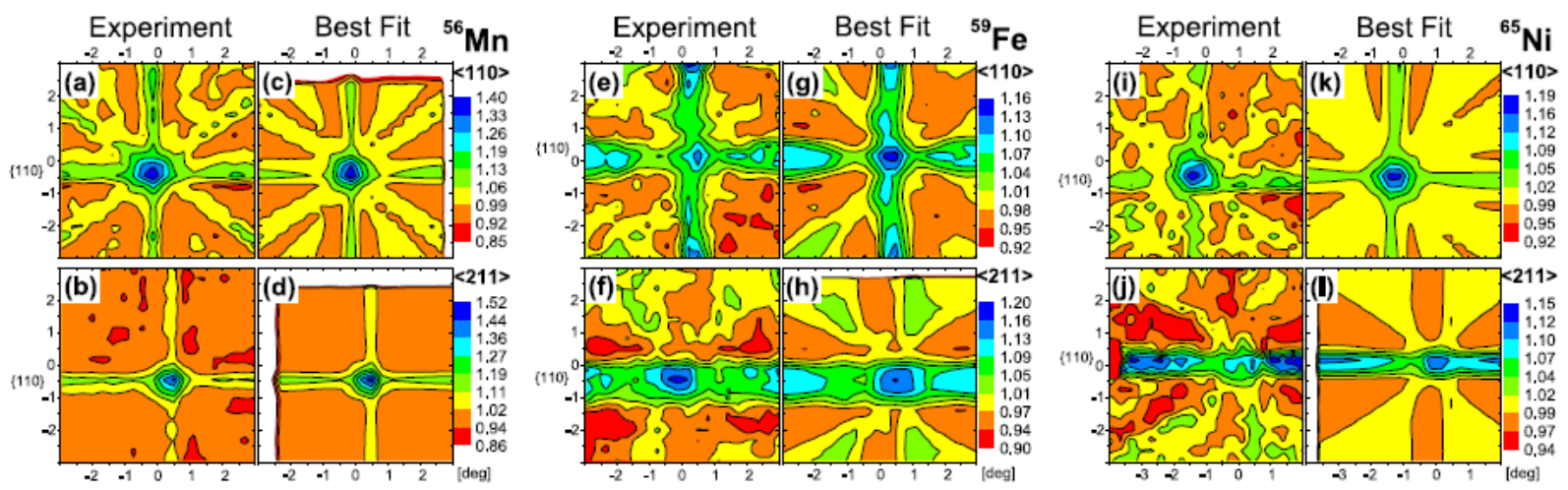

Figure 4. Normalized experimental $\beta^{-}$EC patterns from ${ }^{56} \mathrm{Mn}$ (a) and (b), ${ }^{59} \mathrm{Fe}(\mathrm{e})$ and (f) and ${ }^{65} \mathrm{Ni}(\mathrm{i})$ and (j) and corresponding best fits for a combination of near- $S_{\mathrm{Si}}$ and ideal- $T_{\mathrm{C}}$ sites, along the $\langle 110\rangle$ and $\langle 211\rangle$ directions following annealing at $500{ }^{\circ} \mathrm{C}$.
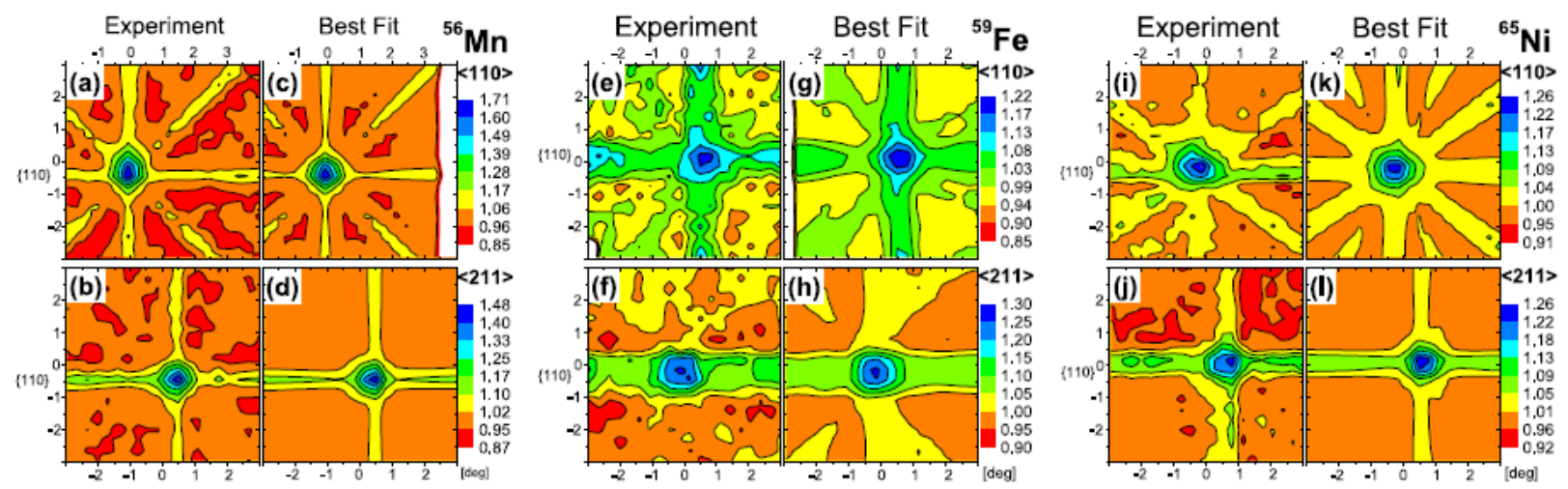

Figure 5. Normalized experimental $\beta^{-}$EC patterns from ${ }^{56} \mathrm{Mn}$ (a) and (b), ${ }^{59} \mathrm{Fe}(\mathrm{e})$ and (f) and ${ }^{65} \mathrm{Ni}(\mathrm{i})$ and (j) and corresponding best fits for a combination of near- $S_{\mathrm{Si}}$ and ideal- $T_{\mathrm{C}}$ sites, in the vicinity of the $\langle 110\rangle$ and $\langle 211\rangle$ directions following annealing at $900{ }^{\circ} \mathrm{C}$.

ing temperatures, below $4 \%$ and hence not very pronounced. We are therefore unable to identify the direction of the displacements unambiguously. The simulations for Fe are presented as an example in figures 6(b), (d) and (e); this also applies to the other TM atoms studied in the present investigations.

Detailed analysis of the ${ }^{59} \mathrm{Fe}$ measurements following various annealing temperatures can be found in the supplementary material (available from: stacks.iop.org/JPhysD/ 50/215101/mmedia). Taking the displacement from $S_{\mathrm{Si}}$ to $\mathrm{AB}_{\mathrm{Si}}$ as an example, figure 7 shows the site for which the best two-site fit was obtained as a function of annealing temperature for all three isotopes. The displacement decreases in all three cases to values $<0.1 \AA$ following annealing at $900{ }^{\circ} \mathrm{C}$, indicating the local recovery of the damaged lattice leading to better incorporation of the TM impurities on the substitutional Si position.

Although the direction of a displacement from substitutional sites could not be pinpointed, our results on the other hand clearly rule out TM atoms on BC positions (which are prominent for some TM atoms in Si [21-25]) within the framework of two-site fits.

The possibility of more than two regular sites being occupied was also explored. In particular, tetrahedral interstitial Si-coordinated $\left(T_{\mathrm{Si}}\right)$, carbon substitutional $\left(S_{\mathrm{C}}\right)$ sites with bond-centered positions were also analysed. For example, a combination of the sites $S_{\mathrm{Si}}+T_{\mathrm{C}}+T_{\mathrm{Si}}$ yielded $T_{\mathrm{Si}}$ frac- tions that were always negative or very close to zero. Similarly, three-site fits allowing for $S_{\mathrm{C}}\left(S_{\mathrm{Si}}+T_{\mathrm{C}}+S_{\mathrm{C}}\right)$ also gave a $\chi^{2}$ reduced by $<5 \%$.

For the fraction analysis as a function of annealing temperature presented in figure 8 and discussed in the following, the fits were confined to two lattice positions: ideal interstitial $T_{\mathrm{C}}$ sites and near-substitutional $\mathrm{Si}$ sites. However, since the analysis results with $S_{\mathrm{C}}$ or BC as third sites are inconclusive, we cannot exclude the possibility that these positions are occupied to some smaller extent by the TM probes.

Figure 8 shows the fitted fractions for the two considered sites, ideal tetrahedral C-coordinated interstitial $T_{\mathrm{C}}$, and nearsubstitutional $\mathrm{Si}$, and 'random' sites that give an isotropic emission distribution, as a function of annealing temperature for all three TMs. The ideal- $T_{\mathrm{C}}$ sites dominate the patterns in the as-implanted state with $28 \%$ for ${ }^{56} \mathrm{Mn}, 50 \%$ for ${ }^{59} \mathrm{Fe}$ and $40 \%$ for ${ }^{65} \mathrm{Ni}$, in contrast to only $15 \%, 11 \%$ and $7 \%$, respectively, on near- $S_{\mathrm{Si}}$ sites. This situation remains unchanged following annealing up to $400{ }^{\circ} \mathrm{C}$ for ${ }^{65} \mathrm{Ni}$, $500{ }^{\circ} \mathrm{C}$ for ${ }^{56} \mathrm{Mn}$ and $600{ }^{\circ} \mathrm{C}$ for ${ }^{59} \mathrm{Fe}$. Then the TM fraction on ideal- $T_{\mathrm{C}}$ sites decreases with further annealing, indicated by the vanishing of the blocking planes around the $\langle 110\rangle$ and $\langle 211\rangle$ directions, whereas the TM fraction on near- $S_{\mathrm{Si}}$ sites increases, indicated by the presence of electron channeling anisotropy peaks in both directions (figures 4 and 5). In all samples, the sum of the two fitted fractions stays be- 

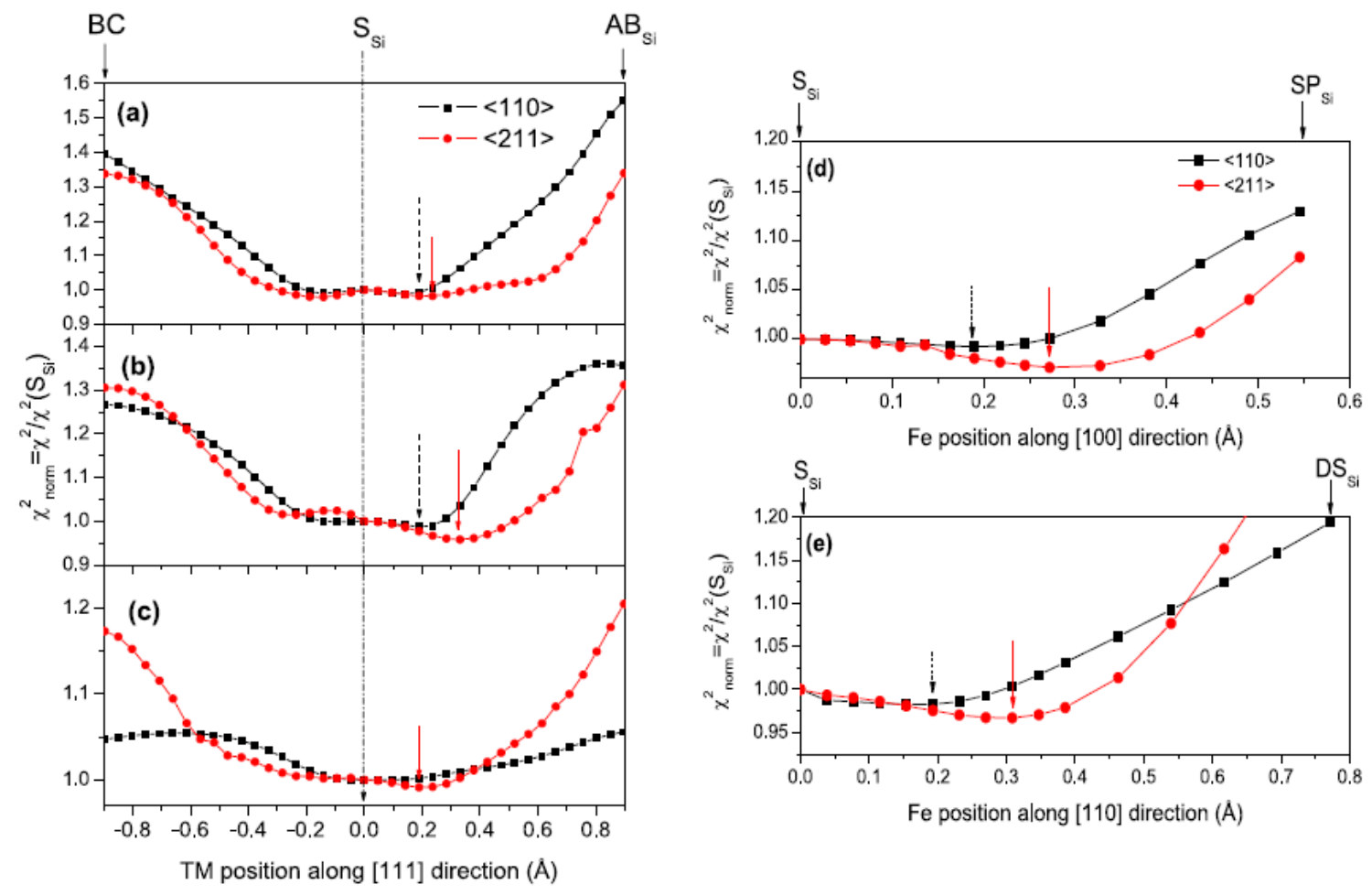

Figure 6. Normalized $\chi^{2}$ norm of two-site fits to $\langle 110\rangle$ and $\langle 211\rangle$ patterns as a function of displacement from ideal $S_{\mathrm{Si}}$ for ${ }^{56} \mathrm{Mn}(\mathrm{a}),{ }^{59} \mathrm{Fe}$ (b) and ${ }^{65} \mathrm{Ni}(\mathrm{c})$. While the first site was kept fixed at the ideal tetrahedral carbon interstitial $\left(T_{\mathrm{C}}\right)$, the position of the second site was moved in small steps along the $\langle 111\rangle$ direction from $S_{\mathrm{Si}}$ towards $\mathrm{AB}_{\mathrm{Si}}$ and $\mathrm{BC}$. In the ${ }^{59} \mathrm{Fe}$ case, we also present displacements along $\langle 100\rangle$ towards $\mathrm{SP}_{\mathrm{Si}}(\mathrm{d})$ and along $\langle 110\rangle$ towards $\mathrm{DS}_{\mathrm{Si}}$ sites (e). The $\chi^{2}$ was in all cases normalized to that for the two-site fit of ideal $T_{\mathrm{C}}$ and ideal $S_{\mathrm{Si}}$. The dashed and full arrows indicate the displacement positions where the lowest $\chi^{2}$ was obtained. All graphs in this figure refer to RT as-implanted measurements; in the case of ${ }^{59} \mathrm{Fe}$ corresponding plots for measurements after annealing have been included in the supplemental material (stacks.iop.org/JPhysD/50/215101/mmedia).

low $100 \%$ throughout the measurements, with the remaining fraction located at random sites. While the increase of the fraction on near-substitutional $\mathrm{Si}$ sites follows the decrease of the ideal- $T_{\mathrm{C}}$ site fraction to some extent, at the same time the sum fraction decreases, which means that some of the TM atoms are moving to random positions instead of occupying $S_{\mathrm{Si}}$. This observation suggests that the TM atoms located at TC positions are probably isolated, with no $\mathrm{Si}$ vacancies available in their vicinity.

As was already mentioned, several theoretical works [12, 14-16] have suggested that the $3 \mathrm{~d}$ TM impurities, from a thermodynamic point of view, should preferentially replace the host lattice Si atoms. It is estimated from SRIM [34] (for a temperature of $0 \mathrm{~K}$, i.e. neglecting dynamic thermal annealing) that each implanted TM atom creates around 300-400 Si vacancies, as well as a similar number of $\mathrm{C}$ vacancies and the corresponding interstitials. The initial vacancy distribution is approximately described by a Gaussian profile centered at somewhat more than half of the projected range of the implantation. The damage created therefore offers ample possibilities for TMs to be incorporated into various types of lattice sites and form complexes with other crystal defects. Especially, since ion implantation is a process that happens far from thermodynamic equilibrium, implanted impurities may therefore also occupy sites that are not the most stable from an energetic point of view. As mentioned above, a smaller fraction of TM atoms was found occupying ideal- $S_{\mathrm{Si}}$ sites in the as-implanted state, while the major fraction remained on interstitial sites. It is thus feasible that, during annealing, interstitial TM atoms may react with Si vacancies, leading to their incorporation on substitutional Si lattice sites. Indeed, concerning TM atoms found on near- $S_{\mathrm{Si}}$ sites, their fractions increase with annealing temperature but, as mentioned before, this increase does not

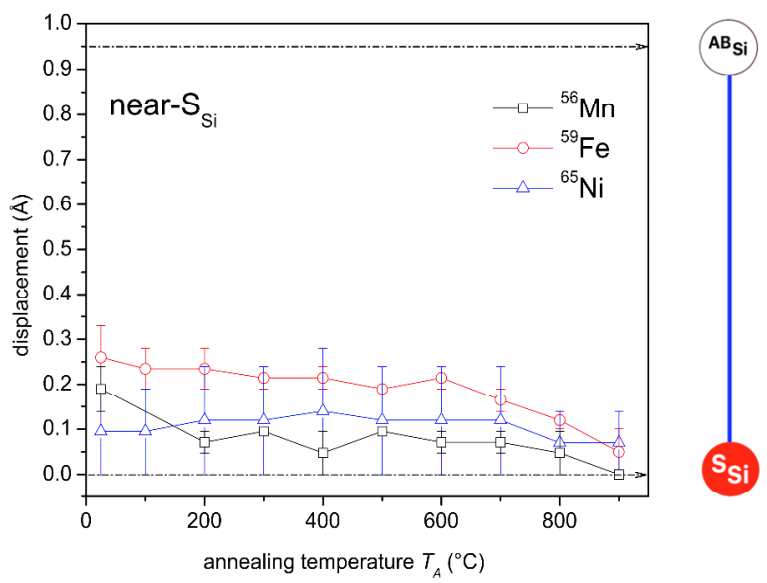

Figure 7. Displacements of the TM impurities from the ideal $S_{\mathrm{Si}}$ towards the $\mathrm{AB}_{\mathrm{Si}}$ site as a function of annealing temperature as derived from best two-site fits with the first site kept fixed at the ideal $T_{\mathrm{C}}$ position. 
totally reflect the observed loss in the ideal- $T_{\mathrm{C}}$ fraction after annealing above $400-500{ }^{\circ} \mathrm{C}$. Furthermore, the total fitted TM sum fractions always stay below $100 \%$ (figure 8 ). The following aspects contribute in providing a possible explanation for this behavior.

First, irradiation-induced silicon mono-vacancies $\left(V_{\mathrm{Si}}\right)$ have been theoretically predicted $[43,44]$ and experimentally observed [45, 46]. Itoh et al [47], by using electron spin resonance, found three annealing stages, at $150{ }^{\circ} \mathrm{C}$, $350{ }^{\circ} \mathrm{C}$ and $750{ }^{\circ} \mathrm{C}$, for the so-called $\mathrm{T} 1$-center, which was later $[45,46]$ identified by the same authors as a negatively charged silicon vacancy. Based on ab initio theoretical modeling, Bockstedte et al proposed the following mechanisms for the $V_{\mathrm{Si}}{ }^{-}$annealing stages [48]: (i) initial recombination of Frenkel pairs with a small separation between the Si vacancy and interstitial, having a low activation energy barrier of $0.2 \mathrm{eV}$; (ii) recombination of vacancies and interstitials with a larger separation that is limited by diffusion of the interstitials with a migration barrier of $1.4 \mathrm{eV}$; (iii) in intrinsic or compensated material, $V_{\mathrm{Si}}{ }^{-}$was predicted to be metastable, transforming into a carbon vacancy-antisite complex $\left(V_{\mathrm{Si}} \rightarrow V_{\mathrm{C}}-\mathrm{C}_{\mathrm{Si}}\right)$ with an energy barrier of $2.5 \mathrm{eV}$. This latter value was in reasonable agreement with the activation energy of $2.2 \mathrm{eV}$ observed by Itoh et al [46, 47] related to the final annealing stage of the $\mathrm{T} 1$ center.

Second, reports on TM diffusion in $\mathrm{SiC}$ are scarce [49, 50]; the most detailed work available [50] studied the tracer diffusions of $\mathrm{Fe}, \mathrm{Cr}$ and $\mathrm{Co}$ in microcrystalline $3 \mathrm{C}-\mathrm{SiC}$ using macroscopic characterization of the diffusion profiles in the temperature range $700-1600{ }^{\circ} \mathrm{C}$. In the case of $\mathrm{Fe}$, the temperature dependence of the diffusion coefficient $D$ was expressed by $D=8.7 \times 10^{-11} \mathrm{~cm}^{2} \mathrm{~s}^{-1} \exp \left(-1.15 \mathrm{eV} / k_{\mathrm{B}} T\right)$. As was noted by the authors of [50], the small value of the activation energy $E_{\mathrm{D}}=1.15 \mathrm{eV}$ points towards an interstitial mechanism of diffusion. However, the pre-exponential factor $D_{0}=8.7 \times 10^{-11} \mathrm{~cm}^{2} \mathrm{~s}^{-1}$ which they derived is many orders of magnitude smaller than what one expects for typical interstitial migration, where $D_{0}$ should be in the range 1$10^{-3} \mathrm{~cm}^{2} \mathrm{~s}^{-1}$ [51]. Below, we will give arguments for why the activation energy for TM diffusion $E_{\mathrm{D}}$ is likely to be higher than $1.15 \mathrm{eV}$. Nonetheless, the finding that Fe longrange diffusion was observed at temperatures around $700{ }^{\circ} \mathrm{C}$ remains valid and, if one uses the above formula from [50], one could estimate that the mean diffusion width $(6 D t)^{1 / 2}$ during a $10 \mathrm{~min}$ anneal at $700{ }^{\circ} \mathrm{C}$ would be $\sim 59 \AA$.

Third, there are effects related to implantation damage and its annealing. Due to this damage, some of the implanted TM dopants are embedded in defective regions. Also, electrons emitted by probe atoms located in defect-free crystalline surroundings may travel through regions of extended damage, both of which increases the de-channeling probability and thus cause the electron emission to be more isotropic. SiC has strong chemical bonds and hence implantation-induced defects have reduced mobility, thus requiring annealing at temperatures above $1400{ }^{\circ} \mathrm{C}$ for near-perfect crystal lattice recovery. Nevertheless, several experimental studies [52-54] showed that for low fluences of implanted heavy ions $\left(<10^{15} \mathrm{~cm}^{-2}\right)$, considerable recovery is already achievable at annealing temperatures below $600{ }^{\circ} \mathrm{C}$. So the overall fraction increase observed up to $500{ }^{\circ} \mathrm{C}$ does not

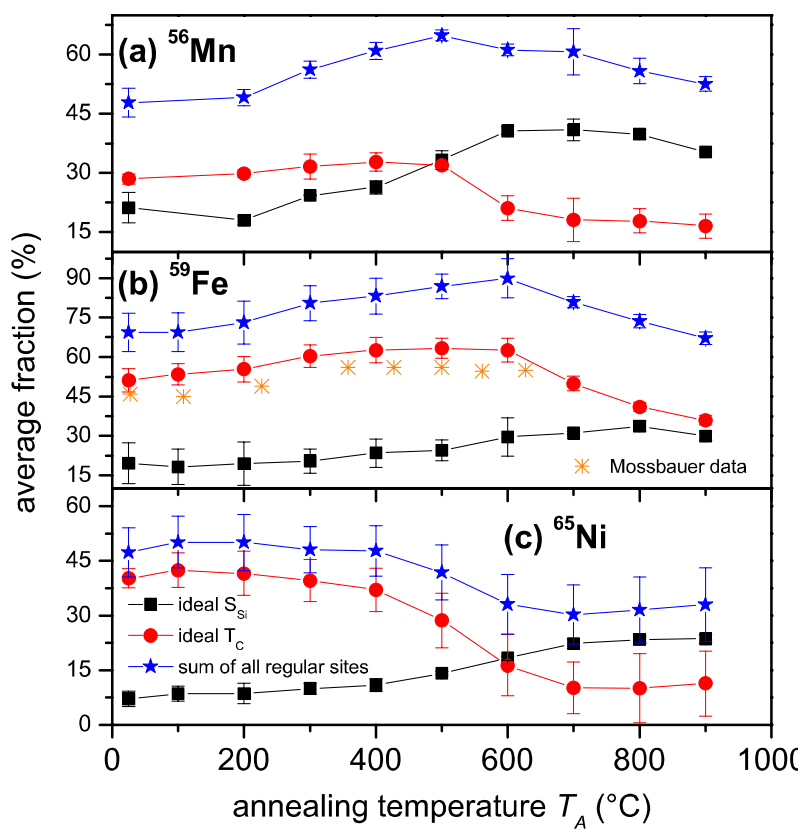

Figure 8. Fitted fractions of ${ }^{56} \mathrm{Mn}(\mathrm{a}),{ }^{59} \mathrm{Fe}$ (b) and ${ }^{65} \mathrm{Ni}$ (c) emitter atoms on near-substitutional $\mathrm{Si}$ (in black) and ideal interstitial $T_{\mathrm{C}}$ sites (in red) plus the sum of both site fractions (in blue) as a function of the annealing temperature, averaged for the four measured crystallographic directions. The error bars represent the spread in fitted fractions for the different crystallographic directions. In panel (b) the sum fraction of ${ }^{57} \mathrm{Fe}^{*}$ on interstitital $\left(T_{\mathrm{Si}}+T_{\mathrm{C}}\right)$ sites derived from the Mössbauer experiments of [29] is shown by orange stars.

necessarily mean that more TM dopants occupy the corresponding lattice sites, but it is likely to be a sign of the local recovery of the defective host lattice.

If we assume that the decrease of the fractions on $T_{\mathrm{C}}$ sites is caused by the onset of interstitial TM diffusion, we can estimate the activation energy $E_{\mathrm{M}}$ for this migration process by using an Arrhenius model, as described e.g. in [22-24]:

$$
E_{\mathrm{M}}=k_{\mathrm{B}} T \ln \left[\frac{\nu_{0} \Delta t_{\mathrm{ann}}}{N \ln \left(\frac{f_{n-1}}{f_{n}}\right)}\right] .
$$

Here $v_{0}$ is the attempt frequency, which we take as $10^{12} \mathrm{~s}^{-1}$, i.e. of the order of the lattice vibrations, $\Delta t_{\mathrm{ann}}$ the annealing time, $T$ the annealing temperature, $f_{\mathrm{n}}$ the interstitial fraction after annealing at $T, f_{n-1}$ the fraction before the annealing at $T$ and $N$ the required number of steps before an interstitial TM atom combines with a silicon vacancy or reaches a random position. We consider two opposite scenarios for $N$ : (1) an upper limit estimate for the migration energy $E_{\mathrm{M}}$ is obtained if one jump is considered enough to move a TM atom into a $\mathrm{Si}$ vacancy or a random position; (2) reaching a lower limit estimate for $E_{\mathrm{M}}$ requires making reasonable assumptions on the maximum number of jumps $N_{\max }$ that take place before the $\mathrm{TM}_{\mathrm{i}}$ reaches a $\mathrm{Si}$ vacancy or a random position. Here we assume that this is quite likely if the diffusion-induced broadening of the TM depth profile would reach a value that corresponds to the projected range $R_{\mathrm{p}}$ of the implantation. This would mean that a large fraction of 
TM probes would reach the surface or diffuse so deeply into the sample that the channeling effects would be damped considerably due to de-channeling. Both cases, diffusion to the surface and into the depth of the sample, lead to a loss of channeling effects which presents as a decrease in the sum fraction of emitter atoms. We note that since such a decrease in the sum fractions is as a matter of fact observed in $\mathrm{SiC}$ for temperatures above $500-600^{\circ} \mathrm{C}$, this scenario with $N_{\max }$ is actually not unlikely. The diffusion-induced broadening resulting from a number of $N$ jumps can be estimated by $\left(r_{\mathrm{M}}^{2} N / 3\right)^{1 / 2}$, where $r_{\mathrm{M}}$ is the mean jump width. If we assume that $r_{\mathrm{M}}$ is given by the closest distance between two interstitial C-coordinated $T_{\mathrm{C}}$ sites, which is $3.08 \AA$ along $\langle 110\rangle$ directions, one calculates $N_{\max } \approx 16180$.

Looking at the estimated values for the $\mathrm{TM}_{\mathrm{i}}$ migration energies $E_{\mathrm{M}}$ presented in table 4, we make the following comments. First, since the fraction of interstitial $\mathrm{Fe}\left(T_{\mathrm{C}}\right)$ decreases only at higher annealing temperatures $\left(T_{\mathrm{A}}=600-\right.$ $\left.900{ }^{\circ} \mathrm{C}\right)$ than in the case of $\mathrm{Mn}$ and $\mathrm{Ni}\left(T_{\mathrm{A}}=400-700{ }^{\circ} \mathrm{C}\right)$, the estimated $E_{\mathrm{M}}$ for $\mathrm{Fe}(3.0 \mathrm{eV})$ is higher than for $\mathrm{Mn}$ and $\mathrm{Ni}(2.6 \mathrm{eV}$ and $2.4 \mathrm{eV})$. Second, the range of $\mathrm{TM}_{\mathrm{i}}$ migration energies overlaps with the activation energy of the third $V_{\mathrm{Si}}$ annealing stage $(2.2 \mathrm{eV}[46,47]-2.5 \mathrm{eV}$ [48]), where the metastable $\mathrm{Si}$ vacancy supposedly converts to a complex $V_{\mathrm{C}}-\mathrm{C}_{\mathrm{Si}}$ antisite defect. This could provide an explanation for why not all of the TMs that were initially interstitial are incorporated in substitutional $\mathrm{Si}$ sites: if $\mathrm{Si}$ vacancies are depleted and there are no other stable lattice sites for diffusing TMs to be found, long-range diffusion and subsequent incorporation in random sites will occur.

$\mathrm{Fe}$ in $\mathrm{SiC}$ has also been investigated using ${ }^{57} \mathrm{Mn} \rightarrow{ }^{57} \mathrm{Fe}$ MS studies, in 3C-SiC by Bharuth-Ram et al [29] and in $6 \mathrm{H}-\mathrm{SiC}$ by Gunnlaugsson et al [30]. The MS technique gives information on the charge distribution in the local environment of the probe atom via the hyperfine interaction and can thus be seen as a complementary technique to the EC method, which reveals the position of the probe atoms with respect to the three-dimensional lattice but lacks sensitivity to their immediate local environment. The comparison of 59Fe lattice location (via EC of emitted electrons) and ${ }^{57} \mathrm{Mn} \rightarrow{ }^{57} \mathrm{Fe}$ hyperfine interaction (via MS of emitted gamma particles) thus offers the possibility of obtaining a more detailed understanding. In the MS experiments, the radioactive probe ${ }^{57} \mathrm{Mn}\left(t_{1 / 2}=1.45 \mathrm{~min}\right)$ was implanted at ISOLDE as a function of temperature, simultaneously to MS measurements taking place during the subsequent decay of the well-known $14.4 \mathrm{keV}$ excited Mössbauer state ${ }^{57} \mathrm{Fe}^{*}$ (98 ns), which is populated by $\beta^{-}$decay of ${ }^{57} \mathrm{Mn}$. A direct comparison of the site fractions of EC versus Mössbauer results as a function of annealing/implantation temperature is hence complicated by the fact that in our EC experiments thermally induced changes are triggered by conventional annealing steps of $10 \mathrm{~min}$ duration, while in ${ }^{57} \mathrm{Mn} \rightarrow{ }^{57} \mathrm{Fe}$ Mössbauer experiments the dominant timescale for probing such changes is the $140 \mathrm{~ns}$ lifetime of ${ }^{57} \mathrm{Fe}^{*}$.

Following RT implantation into 3C-SiC, Bharuth-Ram et al [29] reported the presence of $\sim 15 \%$ of ${ }^{57} \mathrm{Fe}$ probes at substitutional sites (with no possibility of distinguishing between $\mathrm{C}$ and Si sites) and $20 \%$ each on tetrahedral interstitial $\mathrm{C}$ and $\mathrm{Si}$ sites. The site fractions were evaluated up to $\sim 600{ }^{\circ} \mathrm{C}$ implantation temperature, where the substitutional fraction had increased to $\sim 20 \%$, the fraction at $T_{\mathrm{C}}$ sites to $\sim 50 \%$ and the fraction at $T_{\mathrm{Si}}$ sites almost disappeared to $\sim 5 \%$. The site change from $T_{\mathrm{Si}} \rightarrow T_{\mathrm{C}}$ was explained as a thermally activated jump to a more stable position during the $140 \mathrm{~ns}$ lifetime of the ${ }^{57} \mathrm{Fe}^{*}$ Mössbauer state, which allowed deriving an activation energy of $0.8(2) \mathrm{eV}$ for this jump. Similar results had been obtained earlier in $6 \mathrm{H}-\mathrm{SiC}$ [30]. We start the comparison to our results by addressing Fe on TSi sites. As already stated, we are unable to detect the occupation of more than two sites. Although a combination of three sites was tried $\left(S_{\mathrm{Si}}+T_{\mathrm{C}}+T_{\mathrm{Si}}\right)$, in this case the $T_{\mathrm{Si}}$ fraction was close to zero $(<5 \%)$ after implantation and then reached a negative fraction in the earlier annealing stages. According to the MS results, the absence of Fe on $T_{\mathrm{Si}}$ sites would be perfectly understandable since, with an activation energy of $0.8 \mathrm{eV}$, the transformation to the more stable TC sites would require only $\sim 1 \mathrm{~min}$ at $\mathrm{RT}$, thus taking place already during the implantation, which took about $1 \mathrm{~h}$ for this sample, and in any case long before we start measurements with the ${ }^{59} \mathrm{Fe}$ isotope of $45 \mathrm{~d}$ half life. On the other hand, the total interstitial fraction $\left(T_{\mathrm{Si}}+T_{\mathrm{C}}\right)$ seen by $\mathrm{MS}$, which has also been included in figure 8 , remains relatively constant at $45-56 \%$ in between $\mathrm{RT}$ and $600{ }^{\circ} \mathrm{C}$, which is rather similar to the value that we obtained by $\mathrm{EC}$, i.e. $50-$ $60 \%$ for the $T_{\mathrm{C}}$ site. Finally, concerning the substitutional site, we also find a similar fraction at RT with $11 \%$, in our case, on the near- $S_{\mathrm{Si}}$ site and a similar annealing trend also reaching a fraction of $\sim 20 \%$ at $600{ }^{\circ} \mathrm{C}$. Note that site changes from $T_{\mathrm{C}}$ to $S_{\mathrm{Si}}$ with $\mathrm{EM}=2.2-3.0 \mathrm{eV}$, as were observed by ${ }^{59} \mathrm{Fe}$ EC around $700{ }^{\circ} \mathrm{C}$, should not be visible by MS, since for ${ }^{57} \mathrm{Fe}^{*}$ to make one such jump during its $140 \mathrm{~ns}$ lifetime, temperatures above $\sim 1900{ }^{\circ} \mathrm{C}$ would be required. Summarizing, taking into account the different annealing timescales to which the experimental methods are sensitive, in the case of Fe we found good agreement with the results of ${ }^{57} \mathrm{Mn} \rightarrow{ }^{57} \mathrm{Fe} \mathrm{MS}$.

Finally, we would like to compare the current experiments on ${ }^{56} \mathrm{Mn},{ }^{59} \mathrm{Fe}$ and ${ }^{65} \mathrm{Ni}$ in $3 \mathrm{C}-\mathrm{SiC}$ to our previous lattice location results that we obtained for the same probe atoms in $\mathrm{Si}$ [21-25]. A striking difference is that in $\mathrm{Si}$ (with the exception of highly $p^{+}$-doped $\mathrm{Si}$, see the remark below) the major lattice sites in the RT as-implanted state were sites that in a perfect lattice would be located in the vicinity of the BC positions. Our understanding was that these are TMs that are located within multi-vacancy defects such as divacancies and hexa-vacancy rings. As discussed above, although we cannot rule out a smaller fraction of TMs in such positions in $3 \mathrm{C}-\mathrm{SiC}$, they are certainly not the dominating lattice sites. In contrast, in $3 \mathrm{C}-\mathrm{SiC}$ the dominating lattices sites in the RT as-implanted state were in all cases ideal C-coordinated interstitial $T$ sites. The type of site changes, from interstitial to substitutional, that were obvious in $\mathrm{SiC}$ were probably not observed in $\mathrm{Si}$ since they would take place at much lower temperatures: the interstitial TMs obtained during RT implantation in Si should be diffusing so rapidly $\left(E_{\mathrm{M}}(\mathrm{Mn})=0.7 \mathrm{eV}, E_{\mathrm{M}}(\mathrm{Fe})=0.67 \mathrm{eV}\right.$, $\left.E_{\mathrm{M}}(\mathrm{Ni})=0.47 \mathrm{eV}\right)$ that they immediately get attached to traps in the lattice. Our interpretation is that in SiC this interstitial migration process is much slower, with activation 
energies in the $2-3 \mathrm{eV}$ range, so that it is promoted during annealing well above RT and then leads to the increased incorporation of TMs in near-substitutional $\mathrm{Si}$ but also in random sites. In contrast, interstitial sites near the tetrahedral position were generally not observed as dominating TM lattice sites in Si unless the samples were annealed to $600-700{ }^{\circ} \mathrm{C}$. Although the nature of these type of interstitial sites in $\mathrm{Si}$ is not entirely clear, they seem to be associated with long-range TM diffusion and subsequent trapping in the $R_{\mathrm{p}} / 2$ region at around half of the implanted range. We should mention that highly $p^{+}$-doped $\mathrm{Si}$ is a special case since positively charged TM metals are stabilized on or close to tetrahedral interstitial sites also at RT as a consequence of pairing reactions with negatively charged $\mathrm{B}^{-}$acceptors.

\section{Conclusions}

In this work, we experimentally determined the TM impurity lattice location in undoped $3 \mathrm{C}-\mathrm{SiC}$. Following ion implantation into $3 \mathrm{C}-\mathrm{SiC}$, the three TMs $\mathrm{Mn}, \mathrm{Fe}$ and $\mathrm{Ni}$, show similar behavior. Despite the existence of two different sublattices in $\mathrm{SiC}$, in all cases the TMs are preferentially found on interstitial TC and substitutional $S_{\mathrm{Si}}$ sites. This confirms theoretical predictions which have suggested that TMs in $\mathrm{SiC}$ are most stable in C-coordinated positions [12, 14-16]. Whereas in the RT as-implanted state TMs on ideal $T_{\mathrm{C}}$ sites were the prominent species, thermal annealing induced site changes from $T_{\mathrm{C}}$ to both $S_{\mathrm{Si}}$ and random sites. We attribute these site changes to the onset of migration of interstitial TMs, for which we estimate activation energies of EM $=2$ $3 \mathrm{eV}$. There are strong indications that a major feature that can explain characteristic differences in the lattice sites of $\mathrm{TMs}$ in $\mathrm{Si}$ and $\mathrm{SiC}$ is that the migration of interstitial TMs occurs much slower in $\mathrm{SiC}$ than in $\mathrm{Si}$. Also, in contrast to $\mathrm{Si}$, incorporation of $\mathrm{TMs}$ in sites near the $\mathrm{BC}$ position (which are associated with TMs within multi-vacancy complexes) seems to be largely absent. At the highest annealing temperatures, the TM atoms increasingly populate random sites. Since this happens in a temperature regime where the transformation of $V_{\mathrm{Si}} \rightarrow V_{\mathrm{C}}-\mathrm{C}_{\mathrm{Si}}$ has been suggested, a possible explanation is that, once silicon vacancies are unavailable as major traps, the TMs are subject to long-range diffusion.

In summary, the lattice location of TMs in SiC is influenced to a large extent by their ability to interact with other defects and form complexes with them, which will also determine their deep-level properties. We have directly and unambiguously identified the Si site as the preferred TM lattice site. Consequently, the interaction of interstitial TMs with $\mathrm{Si}$ vacancies is of particular relevance and any mechanism that depletes or introduces $V_{\mathrm{Si}}$ in $\mathrm{SiC}$ will play also a critical role in TM lattice site occupation.

\section{Acknowledgments}

We acknowledge the beam time provided by the ISOLDE collaboration. This work was funded by the Portuguese
Foundation for Science and Technology (FCT) through project CERN/FISNUC/0004/2015 and the strategic project UID/Multi/04349/2013, by the FWO Vlaanderen and the KU Leuven (GOA/09/006 and GOA/14/007); ARGC is thankful for FCT grant SFRH/BD/86386/2012 and KB-R for financial support from the National Research Foundation (South Africa). The ISOLDE beam times were supported by the European Commission through the Horizon 2020 program (grant number 654002 ENSAR2).

\section{References}

[1] Neudeck P G 1994 Progress towards high temperature, high power SiC devices Inst. Phys.: Conf. Ser. 141 1-6

[2] Trew R J, Yan J B and Mock P M 1991 The potential of diamond and $\mathrm{SiC}$ electronic devices for microwave and millimeter-wave power applications Proc. IEEE 79 598-620

[3] Wright N G, Horsfall A B and Vassilevski K 2008 Prospects for $\mathrm{SiC}$ electronics and sensors Mater. Today 11 16-21

[4] Kimoto T 2015 Material science and device physics in SiC technology for high-voltage power devices Japan. J. Appl. Phys. 54 1-27

[5] Schneider J and Maier K 1993 Point defects in silicon carbide Physica B 185 199-206

[6] Lebedev A A 1999 Deep level centers in silicon carbide: a review Semiconductors 33 107-30

[7] Baur J, Kunzer M and Schneider J 1997 Transition metals in $\mathrm{SiC}$ polytypes, as studied by magnetic resonance techniques Phys. Status Solidi a 162 153-72

[8] Assali L V C, Machado W V M and Justo J F 2003 Transition metal impurities in 3C-SiC and $2 \mathrm{H}-\mathrm{SiC}$ Physica $\mathrm{B}$ 340-2 $116-20$

[9] Reshanov S A 2000 Growth and high temperature performance of semi-insulating silicon carbide Diam. Relat. Mater. $9480-2$

[10] Dupeyrat C, Declémy A, Drouet M, Debelle A and Thomé L $2010 \mathrm{Fe}$-implanted $\mathrm{SiC}$ as a potential DMS: x-ray diffraction and rutherford backscattering and channelling study Nucl. Instrum. Methods Phys. Res. B 268 2863-5

[11] Bouziane K, Mamor M, Elzain M, Djemia P and Chérif S M 2008 Defects and magnetic properties in Mn-implanted 3C$\mathrm{SiC}$ epilayer on $\mathrm{Si}(100)$ : experiments and first-principles calculations Phys. Rev. B 78195305

[12] Miao M and Lambrecht W 2003 Magnetic properties of substitutional 3d transition metal impurities in silicon carbide Phys. Rev. B 68125204

[13] Takano F, Wang W, Akinaga H, Ofuchi H, Hishiki S and Ohshima T 2007 Characterization of Mn-doped 3C-SiC prepared by ion implantation J. Appl. Phys. 10109 N510

[14] Machado W V M, Justo J F and Assali L V C 2015 Iron and manganese-related magnetic centers in hexagonal silicon carbide: a possible roadmap for spintronic devices J. Appl. Phys. 118045704

[15] Wright E, Coutinho J, Öberg S and Torres V J B 2016 Mössbauer parameters of Fe-related defects in group-IV semiconductors : first principles calculations J. Appl. Phys. 119 181509

[16] Medvedeva N I, Yur'eva E I and Ivanovskii A L 2003 Electronic structure of cubic silicon carbide with substitutional 3d impurities at Si and C sites Semiconductors 37 1243-6

[17] Gubanov V A, Boekema C and Fong C Y 2001 Electronic structure of cubic silicon-carbide doped by $3 \mathrm{~d}$ magnetic ions Appl. Phys. Lett. 78 216-8 
[18] Kawasuso A, Itoh H, Okada S and Okumura H 1996 Annealing processes of vacancy-type defects in electron-irradiated and as-grown $6 \mathrm{H}-\mathrm{SiC}$ studied by positron lifetime spectroscopy J. Appl. Phys. 80 5639-45

[19] Brauer G, Anwand W, Coleman P, Knights A, Plazaola F, Pacaud Y, Skorupa W, Störmer J and Willutzki P 1996 Positron studies of defects in ion-implanted SiC Phys. Rev. B 54 3084-92

[20] Ohshima T, Uedono A, Abe H, Chen Z Q, Itoh H, Yoshikawa M, Abe K, Eryu O and Nakashima K 2001 Positron annihilation study of vacancy-type defects in silicon carbide coimplanted with aluminum and carbon ions Physica B 308-10 $652-5$

[21] Wahl U, Correia J G, Rita E, Araújo J P and Soares J C 2005 Lattice sites of implanted Fe in Si Phys. Rev. B 72014115

[22] Wahl U, Correia J G, Rita E, Araújo J P and Soares J C 2006 $\mathrm{Fe}$ and $\mathrm{Cu}$ in Si: Lattice sites and trapping at implantationrelated defects Nucl. Instrum. Methods Phys. Res. B 253 16771

[23] Silva D J, Wahl U, Correia J G and Araujo J P 2013 Influence of $\mathrm{n}^{+}$and $\mathrm{p}^{+}$doping on the lattice sites of implanted $\mathrm{Fe}$ in Si J. Appl. Phys. 114103503

[24] Silva D J, Wahl U, Correia J G, Pereira L M C, Amorim L M, Da Silva M R, Bosne E and Araújo J P 2014 Lattice location and thermal stability of implanted nickel in silicon studied by on-line emission channeling J. Appl. Phys. 115023504

[25] Silva D J, Wahl U, Correia J G, Amorim L M, Silva M R, Pereira L M C and Araújo J P 2016 Direct observation of the lattice sites of implanted manganese in silicon Appl. Phys. A 122241

[26] Hofsäss H and Lindner G 1991 Emission channeling and blocking Phys. Rep. 201 121-83

[27] Wahl U 2000 Advances in electron emission channeling measurements in semiconductors Hyperfine Interact. 129 349-70

[28] Costa A R G, Wahl U, Correia J G, Bosne E, Amorim L M, Augustyns V, Silva D J, da Silva M R and Pereira L M C to be published

[29] Bharuth-Ram K, Gunnlaugsson H P, Mantovan R, Naicker V V, Naidoo D, Sielemann R, Weyer G and Aigne T 2008 Mössbauer study of Fe in $3 \mathrm{C}-\mathrm{SiC}$ following ${ }^{57} \mathrm{Mn}$ implantation Hyperfine Interact. 184 207-11

[30] Gunnlaugsson H P and Dietrich M 2006 Identification of substitutional and interstitial $\mathrm{Fe}$ in $6 \mathrm{H}-\mathrm{SiC}$ Hyperfine Interact. 169 1319-23

[31] Jonson B and Richter A 2000 More than three decades of ISOLDE physics Hyperfine Interact. 129 1-22

[32] Kellet M A, Bersillon O and Mills R W 2009 The JEFF-3.1/3.11 Radioactive Decay Data and Fission Yields Sub-Libraries (Paris: Nuclear Energy Agency) (available from JANISJava-based Nuclear Data Information System, a software package from the OECD Nuclear Energy Agency www.oecdnea.org/janis/)

[33] Silva M R, Wahl U, Correia J G, Amorim L M and Pereira L M C 2013 A versatile apparatus for on-line emission channeling experiments Rev. Sci. Instrum. 84073506

[34] Ziegler J F, Ziegler M D and Biersack J P 2010 SRIM-The stopping and range of ions in matter Nucl. Instrum. Methods Phys. Res. B 268 1818-23

[35] Wahl U et al 2004 Position-sensitive Si pad detectors for electron emission channeling experiments Nucl. Instrum. Methods Phys. Res. A 524 245-56

[36] Agostinelli S et al 2003 GEANT4-A simulation toolkit $\mathrm{Nucl}$. Instrum. Methods Phys. Res. A 506 250-303
[37] Peng L M, Ren G, Dudarev S L and Whelan J 1996 Robust parameterization of elastic and absorptive electron atomic scattering factors Acta Crystallogr. A 52 257-76

[38] Schulz H and Thiemann K H 1979 Structure parameters and polarity of the wurtzite type compounds $\mathrm{SiC}-2 \mathrm{H}$ and $\mathrm{ZnO}$ Solid State Commun. 32 783-5

[39] Peng T H, Lou Y F, Jin S F, Wang W Y, Wang W J and Chen X L 2009 Debye temperature of $4 \mathrm{H}-\mathrm{SiC}$ determined by x-ray powder diffraction Powder Diffr. 24 311-4

[40] De Mesquita G 1967 Refinement of the crystal structure of SiC type 6H Acta Crystallogr. 23 610-7

[41] Zywietz A, Karch K and Bechstedt F 1996 Influence of polytypism on thermal properties of silicon carbide Phys. Rev. B 54 1791-8

[42] Stelmakh S, Grzanka E, Wojdyr M, Proffen T, Vogel S C, Palosz W and Palosz B 2007 Neutron diffraction studies of the atomic thermal vibrations in complex materials: application of the Wilson method to examination of micro and nanocrystalline SiC Z. Kristallogr. 222 174-87

[43] Wimbauer T, Meyer B K, Hofstaetter A, Scharmann A and Overhof H 1997 Negatively charged Si vacancy in 4H SiC: a comparison between theory and experiment Phys. Rev. B 56 7384-8

[44] Petrenko T T, Petrenko T L, Bratus V Y and Monge J L 2001

Calculation of hyperfine parameters of positively charged carbon vacancy in SiC Physica B 308 637-40

[45] Kawasuso A, Itoh H, Morishita N, Yoshikawa M, Ohshima T, Nashiyama I, Okada S, Okumura H and Yoshida S 1998 Silicon vacancies in 3C-SiC observed by positron lifetime and electron spin resonance Appl. Phys. A 212 209-12

[46] Itoh H, Kawasuso A, Ohshima T, Yoshikawa M, Nashiyama I, Tanigawa S, Misawa S, Okumura H and Yoshida S 1997 Intrinsic defects in cubic silicon carbide Phys. Status Solidi a 162 173-98

[47] Itoh H, Hayakawa N, Nashiyama I and Sakuma E 1989 Electron spin resonance in electronirradiated 3C SiC J. Appl. Phys. 66 4529-31

[48] Bockstedte M, Mattausch A and Pankratov O 2004 Ab initio study of the annealing of vacancies and interstitials in cubic SiC: vacancy-interstitial recombination and aggregation of carbon interstitials Phys. Rev. B 69235202

[49] Danno K, Saitoh H, Seki A, Shirai T, Suzuki H, Bessho T, Kawai Y and Kimoto T 2012 Diffusion of transition metals in 4H-SiC and trials of impurity gettering Appl. Phys. Express 5 031301

[50] Takano K, Nitta H, Seto H, Lee C G, Yamada K, Yamazaki Y, Sato H, Takeda S, Toya E and Iijima Y 2001 Volume and dislocation diffusion of iron, chromium and cobalt in CVD $\beta$ SiC Sci. Technol. Adv. Mater. 2 381-8

[51] Mehrer H 2007 Diffusion of interstitial solutes in metals Diffusion in Solids ed M Cardona et al (Berlin: Springer) pp 316-26

[52] Jiang W, Weber W J, Lian J and Kalkhoran N M 2009 Disorder accumulation and recovery in gold-ion irradiated 3CSiC J. Appl. Phys. 105 2-7

[53] Jiang W, Weber W. and Thevuthasan S 2001 Ion implantation and thermal annealing in silicon carbide and gallium nitride Nucl. Instrum. Methods Phys. Res. B 178 204-8

[54] Usman M, Nour M, Azarov A Y and Hallén A 2010 Annealing of ion implanted $4 \mathrm{H}-\mathrm{SiC}$ in the temperature range of 100 $800{ }^{\circ} \mathrm{C}$ analysed by ion beam techniques Nucl. Instrum. Methods Phys. Res. B 268 2083-5 